\title{
Endoparasites of donkeys in Dessie and its surround- ings, Northeastern Ethiopia
}

\author{
Tesfaheywet Zeryehun ${ }^{1^{*}}$ and Fekade Tsegaw ${ }^{1}$ \\ ${ }^{1}$ College of Veterinary Medicine, Haramaya University, P.O.Box-301, Dire Dawa, Ethiopia \\ *Corresponding author: College of Veterinary Medicine, Haramaya University, P.O.Box-301, Dire \\ Dawa, Ethiopia.Email: tesfahiwotzerihun@yahoo.com \\ http://dx.doi.org/10.4314/evj.v20i1.6
}

\begin{abstract}
A cross-sectional study was conducted from November, 2014 to April, 2015 in Dessie, northeastern Ethiopia to estimate the prevalence of endoparasites and associated risk factors. For this purpose 504 fecal samples were collected from the selected donkeys. Coproscopic examination showed an overall prevalence of 80.1\% (405/504) gastrointestinal helminthes. Among the helminthes, the strongyle type nematodes (80.1\%) were the dominant ones followed by Parascaris equorum (41.8\%) while Anaplocephala spp. was the least identified helminthes. Strongyle spp. was highly prevalent in adult (84.2\%) than old (78.8\%) and young (72\%) age groups $(\mathrm{p}=0.025)$. On the contrary $P$. equorum was highly prevalent in young animals $(62.6 \%)(p=0.000)$ while there was no significant difference in prevalence of Fasciola spp and G. egypticus among age groups ( $\mathrm{p}=0.000)$. Most $43.1 \%$ of donkeys were severely infected. Of these donkeys $49.5 \%(47 / 174)$ were with poor body conditions. Coprocultural examination revealed that (100\%) of Cyathostomes spp. and Strongylus vulgaris and (94\%) of Trichostrongylus axei, (44.0\%) Strongloides westeri and Dictyocaulus arnfieldi. The higher prevalence of parasitosis in working donkeys in Dessie and its surroundings requires appropriate strategic parasitic control methods.
\end{abstract}

Keywords: Coproculture, Coproscopy, Dessie, Helminthes, Prevalence, Risk factors 


\section{Introduction}

Ethiopia has the largest livestock population among other Africa countries with estimated 35 million tropical livestock unit. This includes 31 million cattle, 42 million sheep and goats, 7 million equines, 1.2 million camels and more than 53 million chickens and immense bee and fishery resources. Still $50 \%$ of equine population of Africa is found in Ethiopia (CTA, 1997).

Equines play an important role in rural communities providing power and transport at low cost. They are commonly used for various agricultural operations such as plowing. They also provide the much needed transport in rural areas for activities such as carrying water, building materials, agricultural products and people. Horses and mules are faster and more powerful animals for work but it is more costly to buy and maintain them than donkeys (Pearson et al., 2003). Despite its huge population size, donkey remains marginal due to high prevalence of malnutrition, management constraints and diseases like parasites. Parasitism represents a major obstacle to development of the livestock farming system in the country (Yilma Jobre et al., 1991).

Gastrointestinal parasites are a serious health hazards, contributing to poor body condition, reduced power output, poor productive performance and short life span (Pandey et al., 1994). Studies have indicated that donkeys in Ethiopia are host for large numbers of internal parasites and the vitality and other wellbeing of all ages are threatened by variety of internal parasites (Fikru Regassa et al., 2005; Mulate Beyene, 2005; Zerihun Asefa et al., 2011).

Despite the huge numbers and the increasing importance of donkeys in the Ethiopian economy, knowledge about the health problems affecting their welfare is limited for most parts of the country. The importance of donkey helminthosis is not studies in Dessie and its surroundings. Therefore, the objective of this study was to estimate the prevalence of helminthes parasites and its associated risk factors in donkey in Desse city, northeastern Ethiopia.

\section{Material and Methods}

\section{Description of the study area}

The present study was conducted from 2014 to April 2015 in Dessie and its 
surroundings which is located in western Amhara Regional state. Dessie is located in South Wollo Province of Amhara Regional state $401 \mathrm{~km}$ North of Addis Ababa. The area has an altitude of 2600 up to 3010 meter above sea level. It has a temperature that ranges from $18^{\circ}-25^{\circ} \mathrm{C}$. The main rainy season is from June to August. The feed source for donkeys and other grazing animals is $60 \%$ grazing, $37 \%$ crop residues and the remaining $3 \%$ improved forage. Animal production system is mainly mixed crop-livestock type of farming system (CSA, 2004).

\section{Study animal and design}

Between 2014 to April 2015 a total of 504 donkeys brought to Dessie veterinary clinic either for deworming or other maladies were randomly selected and examined for presence of endoparasites. Risk factors like age and body condition were examined for their association with the outcome. Animals of different age group and body condition scores were included in the study. The age of donkeys were categorized as young ( $<2$ years), adult (2-10 years) and old ( $>10$ years) by the dentition method described by Pearson and Ouassat (2000). These age classes were based on age of first work, productive age and the life span of Ethiopian donkeys (Svedsen, 1997). Body condition score of donkeys was carried out by the classification method used by Henneke et al. (1983) as good and poor.

\section{Fecal sample collection and examination}

Fecal samples were collected directly from the rectum of each animal and placed in a sample collecting bottle (screw capped bottle) and transported to laboratory. Both qualitative and quantitative parasitological techniques were employed. For corposcopic examination of the fecal samples, simple test tube flotation and sedimentation techniques were used as described by Soulsby (1986). Eggs of different helminths were identified on the basis of morphological appearance and size of eggs. McMaster egg counting method was used to determine the number of eggs per gram of feces (EPG) in the positive fecal samples. The degree of severity as determined by the EPG was classified as mild, moderate, heavy and severe nematode infestations for a count of 500 , 800-1000, 1100-1500 and more than 1500, respectively based on previously described methods (Soulsby, 1986; Urquhart et al., 1996). Fecal cultures were done for samples with total mean egg counts of greater than 3000 EPG. Fecal

Ethiop. Vet. J., 2016, 20 (1), 79-90 
culture was carried out according to Kaufmann (1996). The third stage larvae $\left(\mathrm{L}_{3}\right)$ were recovered by Bermann technique. $100 \mathrm{~L}_{3}$ parasites were counted and identification of the hatched $\mathrm{L}_{3}$ was performed on the basis of key morphological differences described by Soulsby (1986) and Kaufmann (1996).

\section{Statistical analysis}

The prevalence of endoparasite was calculated as the number of positive animals divided by the total number of animals examined and multiplied by hundred (Thrusfield, 2005). Association between independent variables (age and body condition score) and parasitism were compared using chi-square (X2) test by SPSS version 20.0 software. Results were reported statistically significant whenever the p-value was less than 0.05 in all analysis.

\section{Results}

\section{Coproscopic examination}

Out of the 504 randomly selected donkeys 405 (80.1\%) were positive for parasites of different species, including nematodes, trematodes and cestodes. Concurrent infections with two or more species of helminthes were more common 259 (51.4 \%) than infections with one 146 (36\%) species of helminthes. Among the helminthes, the strongyle type nematodes $(80.1 \%)$ was the dominant one followed by Parascaris equorum (41.8\%) while Anaplocephala spp. was the least identified helminth (1.6\%) (Figure 1). 


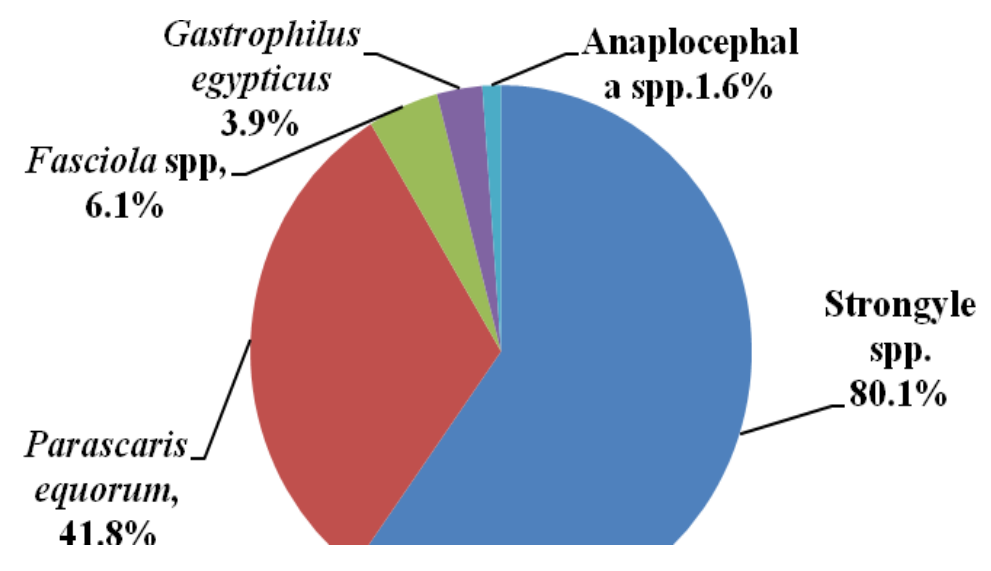

Figure 1: Overall prevalence of helminths in 504 donkeys in Wollo province

In the present study the prevalence of helminth parasites in different age groups (young, adult and old) was determined by coproscopy. The prevalence varies with age and body condition (Table 1 and 2 ). 
Tesfaheywet Zeryehun et al.,

Table 1: Overall prevalence of helminths of donkeys in different age groups in the study area

\begin{tabular}{lcccc}
\hline $\begin{array}{l}\text { Helminth } \\
\text { parasites }\end{array}$ & \multicolumn{1}{l}{ Age } & & $X^{2}$ (p-value) \\
\cline { 2 - 4 } & $\begin{array}{c}\text { Young } \\
(\mathbf{n = 1 0 7 )}\end{array}$ & Adult (n=260) & $\begin{array}{c}\text { Old } \\
(\mathbf{n = 1 3 7 )}\end{array}$ & \\
\hline Strongyle spp. & $77(72 \%)$ & $219(84.2 \%)$ & $108(78.8 \%)$ & $7.382(0.025)$ \\
P. equorum & $67(62.6 \%)$ & $98(37.7 \%)$ & $51(37.2 \%)$ & $21.665(0.000)$ \\
Fasciola spp. & $6(5.6 \%)$ & $13(5.0 \%)$ & $12(8.8 \%)$ & $2.266(0.332)$ \\
G. egypticus & $5(4.7 \%)$ & $6(2.3 \%)$ & $9(6.6 \%)$ & $4.453(0.108)$ \\
Anaplocephala spp. & - & $8(3.1 \%)$ & - & - \\
\hline
\end{tabular}

Table 2: Overall prevalence of helminths of donkeys in different BCS categories in the study area

\begin{tabular}{|c|c|c|c|}
\hline \multirow[t]{2}{*}{ Helminth parasites } & \multicolumn{2}{|c|}{ Body condition score } & \multirow{2}{*}{$\mathrm{X}^{2}$ (P-value) } \\
\hline & Good $(n=391)$ & Poor $(n=113)$ & \\
\hline Strongyle spp. & $309(79.0)$ & $95(84.1)$ & $1.402(0.284)$ \\
\hline P. equorum & $133(34.0)$ & $83(73.5)$ & $55.670(0.000)$ \\
\hline Fasciola spp. & $25(6.4)$ & $6(5.3)$ & $0.178(0.825)$ \\
\hline G. egypticus & $7(1.8)$ & $13(11.5)$ & $21.708(0.000)$ \\
\hline Anaplocephala spp. & $8(2.0)$ & - & - \\
\hline
\end{tabular}

\section{Fecal egg count}

The degree of infection by helminths was determined by EPG of donkeys (Table 3). 
Table 3: Degree of gastrointestinal helminths infection in donkeys in the study area

\begin{tabular}{|c|c|c|c|c|c|}
\hline \multirow{2}{*}{ Risk Factors } & \multicolumn{4}{|c|}{ Degree of infection } & \multirow[t]{2}{*}{ Total } \\
\hline & Mild (\%) & $\begin{array}{c}\text { Moderate } \\
\text { (\%) }\end{array}$ & $\begin{array}{c}\text { Heavy } \\
(\%)\end{array}$ & $\begin{array}{c}\text { Severe } \\
(\%)\end{array}$ & \\
\hline \multicolumn{6}{|l|}{ Age } \\
\hline Young & $12(15.6)$ & $14(18.2)$ & $12(15.6)$ & $39(50.6)$ & $77(100)$ \\
\hline Adults & $27(12.3)$ & $44(20.1)$ & $43(19.6)$ & $105(47.9)$ & $219(100)$ \\
\hline Old & $43(39.8)$ & $18(16.7)$ & $17(15.7)$ & $30(27.8)$ & $108(100)$ \\
\hline Total & $82(20.3)$ & $76(18.8)$ & $72(17.8)$ & $174(43.1)$ & \\
\hline \multicolumn{6}{|l|}{$\begin{array}{l}\text { Body condition } \\
\text { score }\end{array}$} \\
\hline Good & $70(22.6)$ & $60(19.4)$ & $52(16.8)$ & $127(41.2)$ & $309(100)$ \\
\hline Poor & $12(12.6)$ & $16(16.8)$ & $20(21.1)$ & $47(49.5)$ & $95(100)$ \\
\hline Total & $82(20.3)$ & $76(18.8)$ & $72(17.8)$ & $174(43.1)$ & \\
\hline
\end{tabular}

\section{Identification of nematode larvae}

The results of the coprocultural examination revealed six different helminth parasite larvae, (Table 4).

Table 4: Larvae of nematodes identified from coproculture of donkeys in Desse Administrative city

\begin{tabular}{lcc}
\hline Nematode larvae & Number & Percentage \\
\hline Cyathostomes spp. & 36 & 100 \\
Strongylus vulgaris & 36 & 100 \\
Trichostrongylus axei & 34 & 94 \\
Strongylus edentatus & 28 & 77.7 \\
Strongloides westeri & 16 & 44.4 \\
Dictyocaulus arnfieldi & 16 & 44.4 \\
\hline
\end{tabular}

\section{Discussion}

The present study revealed that gastrointestinal nematode infection was an important problem in Dessie and its surroundings with high prevalence (80.1\%). Our finding was comparable with previous studies of Getachew Ayele et al. (2006), Getachew Mulugeta et al. (2010), Zerihun Assefa et al. (2011), 
Ibrahim Nuraddis et al. (2011) and Fikru Regassa et al. (2005), who reported prevalence of $100 \%, 100 \%, 99.5 \%, 96.9 \%$ and $92.8 \%$, respectively, in different part of the country. The difference might be attributed to variations in agroecology, climatic conditions and most likely to the sampling techniques as we sampled animals visiting the Dessie vet clinic. While, the prevalence is higher than other studies made by Bewketu Takele and Endalkachew Nibret (2013) who reported prevalence of $65.09 \%$ in Bahir Dar, Northern Ethiopia. However, the present finding was lower than the work of Shiferaw Yoseph et al. (2001), Mulate Beyene (2005) and Fikru Regassa et al. (2005) who reported 100\%, $100 \%$ and $98.2 \%$ in donkeys of Wonchi, high lands of Wollo province and western highlands of Oromia, respectively.

In this study we also detected polyparasitism like the previous works of Getachew Ayele et al. (2006). Poor management of donkeys and grazing pasture as well as lack of helminth control practice in the current study might have contributed to mixed infection.

In the present study the prevalence of $P$. equorum was $41.8 \%$, which is comparable with the work of Getachew Ayele et al. (2006) and Zerihun Mulat (2008) who reported $43 \%$ and $42.8 \%$ in Duga Bora district and highlands of Wollo province respectively. However, the prevalence in the current study was lower than the observations made by Zerihun Asefa et al. (2011) (53\%) and Mulate Beyene (2005) (50\%), but higher than the report of Teka Tegegn et al. (1999) (34\%) and Fikru Regassa et al. (2005) (17.3\%). The discrepancies in these studies might be attributed to differences in the agro-ecology, climate, and management practices. With regard to the age wise prevalence, as was observed by Zerihun Asefa et al. (2011) and Zerihun Mulat (2008), the prevalence of $P$. equorum was significantly $(\mathrm{p}<0.05)$ higher in young donkeys than the adult and old age groups. This is due to the fact that young donkeys have less immunity against $P$. equorum than the other age groups. Likewise animals with poor body condition were with significantly $(\mathrm{p}<0.05)$ higher prevalence of $P$. equorum than animals with poor body condition. This might be due to the lesser immunity in the poor body condition animals.

The prevalence of Fasciola spp. in this study was $6.1 \%$. This finding was comparable with the previous reports (Zerihun Asefa et al., 2011). However, our finding was higher than previous report by Getachew Ayele et al. (2006) (1.5\%) from Duga Boru district. The high prevalence in the current study might be 
due to the favorable in ecological conditions for the development of intermediate snails and the parasite in the current study area.

A prevalence of 3.9\% was recorded for G. aegypticus in the present study which was in agreement with the findings of Zerihun Asefa et al. (2011) and Getachew Ayele et al. (2006) who reported prevalence of 5.7\% and 6\% in Gefersa and Duga Bora district respectively. Animals with poor body condition were with significantly $(\mathrm{p}<0.05)$ higher prevalence of $G$. aegypticus than animals with poor body condition. This might be due to the lesser immunity in the poor body condition animals or otherwise.

In the present study Anoplocephala sp., was the least recorded heliminth with a prevalence of $1.6 \%$ which was in a close agreement with the research done by Zerihun Asefa et al. (2011) who reported prevalence of 2.7 from Gefersa district. On the other hand Getachew Ayele et al. (2006) documented a higher prevalence of $7.6 \%$ from Duga Bora district. These discrepancies might be related to the seasonality of the orbited mites vectors (Soulsby 1986) and differences in the agro-ecology and climatic conditions among the localities.

In the current study although most donkeys were with severe degree of infection, but the proportion of donkeys with severe degree of infection was higher in animals with poor (49.5\%) than good (41.7\%) body condition. This probably might suggest that body condition score can be used as a good indicator of burden of parasites for owners to identify donkeys which require immediate attention and treatment against helminth parasites. This observation was supported by previous works elsewhere (Getachew Ayele et al., 2006; Brady and Nichols, 2009; Zerihun Assefa et al., 2011).

In this study cultural identification of larvae revealed $100 \%$ prevalence of Cyathostomes spp. and Strongylus vulgaris. Similar observations were made elsewhere in the country (Yoseph et al 2001; Getachew Ayele et al., 2006; Zerihun Assefa et al., 2011). However, prevalence of 3.01\% for Strongylus vulgaris and 63.79\% for Cyathostomes spp. has been reported from Turkey (Umur and Mustafa, 2009). Trichostrongylus axei (97.4\%) was the next prevalent larvae encountered. A prevalence of 100\% Trichostrongylus axei has been documented (Zerihun Assefa et al., 2011). Strongylus edentatus, Strongloides westeri and Dictyocaulus arnfieldi, were other larvae encountered in the ova culture with 
prevalence of $77.7 \%, 44.4 \%$ and $44.4 \%$, respectively. The prevalence of S. edentatus, in this study was in close agreement with the report of Zerihun Assesfa et al. (2011) (73.8\%) but it disagrees with Getachew Ayele et al. (2006) and Nuradis Ibrahim et al. (2011) who reported $64.3 \%$ and $30.8 \%$. The prevalence of $S$. westeri in this study was $44.4 \%$ which disagrees with the work of Ibrahim et al. (2011), Umur and Mustafa (2009), and Getachew Ayele et al. (2006). These authors reported prevalence of $20 \%, 22.58 \%$ and $32 \%$, respectively.

In the present study the prevalence of $D$. arnfieldi was $44.4 \%$ which was in accord with the work of Zerihun Assefa et al. (2011) who reported 42.8\%. But our finding was in disagreement with the finding of Getachew Ayele et al. (2006) (32\%) and Nuraddis Ibrahim et al. (2011) (3.6\%). The discrepancy could be attributed to the difference in agro-climatic condition and sampling methods. According to Beelitz et al. (1996), donkeys are the most important reservoir and potential source of infection to other equine species. In general our finding in the coprocultue revealed a relatively higher prevalence compared with previous reports in the country, which might be related to variations in the agro-ecology, climatic conditions, management systems, and sample size differences.

\section{Conclusions}

The overall prevalence of gastrointestinal helminth parasites in Desse and its surroundings was $80.1 \%$. There is also high prevalence of mixed infections with both nematodes and trematodes. Helminthosis is important health problem. The study showed that nematode parasites were the most predominant parasites compared to trematodes and cestodes. Strategic deworming of animals is recommended to control gastrointestinal helminths in donkeys. Because of polyparasitism effective broad spectrum anti-helminthics is recommended.

\section{Acknowledgements}

The authors would like to thank the Dessie Parasitology Laboratory staff members for the technical assistance rendered during the study period.

\section{References}

Asefa, Z., Bersisa, K., Boja, E. and, Ayele, G., 2011. Endoparasites of donkeys in Sululta and Gefersa districts of central Oromia, Ethiopia. J. Ani. Vet. Adv., 10, 1850-1854. 
Ayele, G., Gebreab, F., Endebu, B. and Joe, A., 2006. A prevalence of gastrointestinal parasites of donkeys in Dugda Bora districts, Ethiopia, Livestock Res. Rural Devt., 18.

Beelitz, P., Gobel, E. and Gothe, R., 1996. Endoparasites of donkeys and horses kept in communal housing in Upper Bavaria; species spectrum and incidence. Tierarztl prax., 24, 471-475.

Beyene, M., 2005. Preliminary study on helminthosis of equines in South and North Wollo zones. Ethiop. Vet. J., 9(2), 25-37.

Brady, H.A. and Nichols, W.T., 2009. Drug resistance in equine parasites: an emerging global problem. J. Vet. Equine Sci., 29, 285-295.

Charles, M.H. and Robinson, E.D., 2006. Diagnostic Parasitology for Veterinary technician $3^{\text {rd }}$ ed, Linda, L, Duncan, Chaina.

CSA, 2005. Central Statistical Agency: The 2001/2002 Ethiopian Agricultural sample enumeration (ease), Executive summary, Addis Ababa, Ethiopia.

CTA, 1997. Technical Center for Agricultural and Rural cooperation: Livestock development policies in Eastern and Southern Africa proceeding of seminar by CTA, OAU/ IBAR and the Ministry of Agriculture and cooperatives, Swaziland, pp 216-220.

Henneke, D., Potter, G., Kreider, J. and Yates, B., 1983. Relationship between condition score, physical measurements and body fat percentage in mares. Equine Vet. J., 15, 371-372.

Jobre Y., Gebreab, F., Svendsen, E.D. and Abdella, M., 1991. Health problems of working donkeys in DebreZeit and Menagesha of Ethiopia 151-161. In Field, D. and Pearson, R.A., (eds), Donkey, Mules and Horses in tropical agricultural development. In Proceedings of colloquium held 3-6 September 1990, Edinburgh, Scotland. Center for Tropical Veterinary Medicine, University of Edinburgh, UK: 336p.

Kaufmann, J.L., 1996. Parasitic infection of domestic animals. A diagnostic manual. Bir havsen Verleg, Germany. pp. 5-21 and 224-227.

Mulat, Z., 2008. The status of strongyle and parascaris population in working donkeys in Central Ethiopia. DVM Thesis, FVM, AAU, Debre Zeit, Ethiopia.

Mulugeta, G., Trawford, A.F., Gebreab, F. and Reid, S.W.J., 2010. Gastrointestinal parasites of working donkeys in Ethiopia. Trop. Ani. Hlth. Prod., 42, 27-33.

Nuraddis, I., Tilahun, B., Benti, D. and Tadele, T., 2011. Survey of prevalence of helminth parasites of donkeys in and around Hawassa Town, Southern Ethiopia, Global Vet., 6 (3), 223-227.

Pandey, V.S., Khallayoune, K., Ouhelli, H. and Dakask, A., 1994. Parasites of donkeys in Africa. In Proceedings of the second colloquium on working equines Bakkoury, 
M. and Prentis, R.A., (Eds). 22-24 April, 1994, Institutes of Agronomi queet veterinary Hassan II. Rabat. Morocco. pp. 35-44.

Pearson, R.A, Timothy, E.S. and Krecek, S., 2003. Harnessing and hitching donkeys, horses and mules for work. Center for Tropical Veterinary Medicine. University of Edinburgh, UK and Department of Agriculture and Rural Engineering. University of Venda for Science and Technology. South Africa, pp. 1.

Pearson, R.A. and Ouassat, M., 2000. A guide to live weight estimation and body condition scoring of donkeys. University of Edinburgh, Center for Tropical Veterinary Medicine, Edinburgh.

Regassa, F., Duguma, R. and Mideksa, B., 2005. Prevalence of gastrointestinal parasites in western highlands of Oromia, Ethiopia. Bull. Ani. Hlth. Prod. Afr., 53, 161-166.

Soulsby E.J.L., 1986. Helminthes, Arthropods and Protozoa of Domesticated Animals, $7^{\text {th }}$ edn. Bailliere Tindall, London, pp. 167-174.

Svedsen, E.D., 1997. Parasite abroad: The professional hand book of the donkey 3rd edition. Whittet Books Limited, London, pp.16-182.

Takele, B. and Nibret, E., 2013. Prevalence of gastrointestinal helminthes of donkeys and mules in and around Bahir Dar, Ethiopia. Ethiop. Vet. J., 17(1), 13-30.

Teka, T., Azeze A. and Gebremariam, A., 1999. Cross border livestock trade and food security in the Southern and Southeastern Ethiopia Border lands. OSSREA, Developmental Report series. No.1 Commercial printing Enterprise. Addis Ababa, Ethiopia. pp. 1-6.

Thrusfield, M., 2005. Sampling in Veterinary Epidemiology. $3^{\text {rd }}$ ed. Blackwell Scince. London. pp. 182-189.

Umur, S. and Mustafa, A., 2009. A survey on helminthes infections of equines in the Central Black Sea region, Turkey. Turkish J. Vet. Ani. Sciences., 33, 373-378.

Urquahart, G. Armour, M., Duncan, J.L., Dunn, A.M. and Jennings, F.W., 1996. Veterinary Parasitology, Churchill Livingston INC, New York. pp. 8-170.

Yoseph, S., Gebreab, F. and Wosene, A., 2001. Survey on helminthosis of equines in Wonchi, Ethiopia. J. Ethiop. Vet. Assoc., 5, 47-61. 